\title{
STUDY OF REDUCED-ENRICHMENT URANIUM FUEL POSSIBILITY FOR RESEARCH REACTORS
}

\author{
V.A. Ruppel ${ }^{1}$, Yu. S. Tretyakova ${ }^{1 a}$, S. V. Lavrinenko ${ }^{1}$, A.A. Matveeva ${ }^{1}$, V.N. Martyshev ${ }^{1}$ \\ ${ }^{1}$ National Research Tomsk Polytechnic University, 634050 Tomsk, Russia
}

\begin{abstract}
Having analyzed the results obtained in the work, it is possible to conclude that the flux density of fast and thermal neutrons in the shell of fuel elements in EFA in REU-zone decreased on average by $5 \%$ for UO2 fuel and by $7 \%$ for U9\%Mo fuel. Change of neutrons flux density during the cycle does not exceed $4 \%$ for both fuel types. On average the fuel burnup in reactor core during the cycle for $\mathrm{UO} 2$ and $\mathrm{U} 9 \%$ Mo increased by $2.8 \%$. It is $1 \%$ less that in HEU-zone, which is conditioned by higher initial loading of $235 \mathrm{U}$ in fuel assembly with REU fuel.
\end{abstract}

\section{Introduction}

Research nuclear plants (RNP) - research reactors (RR), critical (CEF) and sub-critical experimental facilities (SEF) - played an important role in obtaining fundamental and applied knowledge in the field of nuclear physics. Being the source of neutrons, RNP are considered by researchers a unique instrument for investigations in various fields of science and engineering [1]. According to IAEA data 692 RNP of different types and with different power were built all over the world during the period of nuclear physics development [2].

In 1993 cooperation on the development of reduced enrichment fuel for RR exported by Russia started between Russia and the United States. This cooperation within the Reduced Enrichment Program for Research and Test Reactors is being performed now. The purpose of the Reduced Enrichment Program for Research and Test Reactors is to decrease the risk of nuclear materials distribution, as such materials are applicable for nuclear weapon creation; and increase of physical security of nuclear process facilities by removing enriched fuel from reactor cores of RR.

In 2010 the work on technical-economical evaluation of the conversion possibility of RR operating on highly-enriched uranium started. Conclusion of executive agreement between State Atomic Energy Corporation "Rosatom" and the United States Department of Energy was the basis for this. The main agreement requirements were the following:

- power of reactors should remain unchanged ;

- neutrons flux densities in experimental reactors can decrease insignificantly;

- the required value of neutrons flux densities decrease should be approved by operating organizations;

- geometry and dimensions of fuel assemblies should remain unchanged (it is desired to keep the size of nuclear fuel elements);

- economical costs caused by the conversion should be calculated accurately and should not be excessive;

- fuel component of operating expenses should remain unchanged or can be increased insignificantly [3].

The Russian company TVEL developed nuclear fuel based on reduced uranium for the only Polish RR "Maria", which passed reactor testing successfully.

At present full production of new fuel types with reduced enrichment uranium for research reactors has been developed and mastered at TVEL. The company has stopped exporting fuel assemblies with highly-enriched uranium since 2013. Research reactors of Russian design in such countries as Vietnam, Hungary, Libya, Uzbekistan, Ukraine and Czech Republic were switched to reduced enrichment uranium.

Works on the possibilities to switch Russian RR to reduced enrichment uranium continue, at the same time researches on the determination of the optimum composition of such fuel are carried out.

The possibility of conversion for such RR as MIR-M1 (SSC NIIAR), IRT-T (SSI TPU), IR-8 (RRS Kurchatov Institute), IRT (MEPhI) is being discussed.

RR MIR-M1 is considered to be one of the most perspective reactors from the point of view of conversion to reduced enrichment fuel. It is a heterogeneous, loop, channel-type reactor on thermal neutrons immersed into the water pool. It is intended

\footnotetext{
${ }^{a}$ Corresponding author : juliatret.jt@gmail.ru
} 


\section{MATEC Web of Conferences}

for: loop tests on experimental models of fuel elements and fuel assemblies of nuclear reactors of different types and purpose, tests on construction materials and nuclear reactor products of various types and purpose, accumulation of radionuclide products.

In 2004 В 2004 г. the decision on NPP MIR-M1 life extension to 2017 was upheld, providing the reactor plant is improved. The program involves the system and facility modernization without long breaks in operation for works performance, providing the time factor of the reactor use during the year at about $60 \%$ [4].

\section{Study technique and results}

Technological operability possibility of conversion of reactor on dispersion $\mathrm{UO}_{2}$ and $\mathrm{U} 9 \% \mathrm{Mo}$ fuel was considered in the work. In both cases the fuel was dispersed into aluminum matrix, and uranium enrichment was $19.7 \%$. Neutron-physical calculations for evaluation of the reactor parameters were carried out using the MCU-RR program based on the Monte-Carlo method. Change of the nuclide fuel composition, reactor core reactivity, capacity of operating and loop fuel assemblies were calculated using the program MCU-RR with the connected program module BURNUP. In calculations with burnup accumulation of fission products absorbing neutrons only weekly and moderately and reactor poisoning by Xe-135 were considered.

For accurate comparison of the results the calculations were performed:

- at equal reactor power;

- at equal reactor lifetime;

- providing steady conditions of off-line refueling of the reactor operation;

- providing equal reactivity margins at the end of the cycle;

- providing equal duration of annual planned-preventive maintenance;

- providing equal reactor shutdown duration between the cycles.

The calculation results are presented in Table 1 .

Table 1Reactor core characteristics for highly-enriched and reduced enrichment uranium fuel

\begin{tabular}{|c|c|c|c|}
\hline \multirow[b]{2}{*}{ Parameter } & \multicolumn{3}{|c|}{ Value } \\
\hline & $\begin{array}{l}\mathrm{HEU} \\
\mathrm{UO}_{2} \\
\end{array}$ & $\begin{array}{l}\mathrm{REU} \\
\mathrm{UO}_{2}\end{array}$ & $\begin{array}{c}\text { REU } \\
\text { U9\% } \% \text { Mo }\end{array}$ \\
\hline $\begin{array}{c}\text { Fuel assembly overall dimensions: } \\
\text { diameter, } \mathrm{mm} \\
\text { length, } \mathrm{mm}\end{array}$ & $\begin{array}{c}70 \\
1484\end{array}$ & $\begin{array}{c}70 \\
1484\end{array}$ & $\begin{array}{c}70 \\
1484\end{array}$ \\
\hline Concentration of ${ }^{235} \mathrm{U}, \%$ & 90 & 19.7 & 19.7 \\
\hline Average fuel burnup in the reactor core at the beginning of the cycle, $\%$ & 29.5 & 36.0 & 33.8 \\
\hline Average fuel burnup in the reactor core at the end of the cycle, $\%$ & 33.3 & 38.8 & 36.6 \\
\hline $\begin{array}{l}{ }^{235} \mathrm{U} \text { load in fuel assembly, } \mathrm{g} \\
\text { - medium } \\
\text { - maximum } \\
\text { - minimum }\end{array}$ & $\begin{array}{l}246.9 \\
350.0 \\
175.0\end{array}$ & $\begin{array}{l}294.4 \\
417.4 \\
208.7\end{array}$ & $\begin{array}{l}304.5 \\
431.8 \\
215.9\end{array}$ \\
\hline Number of fuel elements & 4 & 6 & 4 \\
\hline Fuel depth thickness in fuel element, mm & 0.56 & 0.94 & 0.66 \\
\hline${ }^{235} \mathrm{U}$ load in reactor core, $\mathrm{kg}$ & 12.6 & 15.01 & 15.53 \\
\hline Power ratio of EFA to power of OFA in unpoisoned condition, rel.u & 0.70 & 0.69 & 0.68 \\
\hline $\begin{array}{l}\text { Neutrons flux density in fuel element shell in middle reactor core plane, } 10^{14} \mathrm{sm}^{-2} \mathrm{~s}^{-1} \text { : } \\
\text { Fast neutrons }(E>0.1 \mathrm{MeV}) \\
\text { - central fuel element } \\
\text { - inner row fuel element } \\
\text { - outer row fuel element } \\
\text { Thermal neutrons }(E<0.5 \mathrm{eV}) \\
\text {-central fuel element } \\
\text {-inner row fuel element } \\
\text {-outer row fuel element }\end{array}$ & $\begin{array}{l}2.05 \\
2.00 \\
1.83\end{array}$ & $\begin{array}{l}1.93 \\
1.89 \\
1.74 \\
\\
1.10 \\
1.20 \\
1.48\end{array}$ & $\begin{array}{l}1.90 \\
1.84 \\
1.70 \\
\\
1.09 \\
1.17 \\
1.44\end{array}$ \\
\hline
\end{tabular}

For $\mathrm{UO}_{2}$ fuel in the reactor core with REU it is suggested to use another type of fuel assembly compared to HEU reactor core. Fuel assembly constructively consists of 6 coaxially placed ring-shaped fuel elements fixed at the top and in the bottom. Each fuel element us a three-layer tube in which the fuel layer is covered by aluminum alloy (CAB-6) on both sides.

For U9\% Mo fuel in the reactor core with REU it is supposed to use conventional construction fuel assembly with increased core thickness and higher density of uranium fuel composition. 
The values of initial loading of ${ }^{235} \mathrm{U}$ in fuel assemblies with REU are higher at bigger average fuel burnup than in active core with HEU. In this case the reactivity margin at the beginning of the cycle in unpoisoned condition, reactivity margin for fuel burnup and fuel poisoning, excessive reactivity in poisoned condition and reactivity loss rate at fuel burnup in REU-zone is smaller. Other characteristics of HEU- and REU-zones at the beginning of the cycle are approximately the same. Core power distribution during the cycle also changes insignificantly. Such result is true for both fuel types.

\section{Conclusion}

Having analyzed the results obtained in the work, it is possible to conclude that the flux density of fast and thermal neutrons in the shell of fuel elements in EFA in REU-zone decreased on average by $5 \%$ for $\mathrm{UO}_{2}$ fuel and by $7 \%$ for $\mathrm{U} 9 \% \mathrm{Mo}$ fuel. Change of neutrons flux density during the cycle does not exceed $4 \%$ for both fuel types.

On average the fuel burnup in reactor core during the cycle for $\mathrm{UO}_{2}$ and $\mathrm{U} 9 \% \mathrm{Mo}$ increased by $2.8 \%$. It is $1 \%$ less that in $\mathrm{HEU}$ zone, which is conditioned by higher initial loading of ${ }^{235} \mathrm{U}$ in fuel assembly with REU fuel. Therefore, the average burnup in uploaded fuel assemblies with REU fuel and the cycle of these fuel assemblies are bigger, but the number of reloaded fuel assemblies will be smaller compared to fuel assemblies with HEU fuel. Moreover, due to higher volume of fuel elements cores in fuel assemblies with HEU fuel, density of fission products in them will be smaller, despite higher burnup of ${ }^{235} \mathrm{U}$.

One more significant reason for conversion to reduced enrichment fuel is the fact that annual consumption of ${ }^{235} \mathrm{U}$ in REUzone is smaller, but annual demand by fuel assemblies is smaller than in currently operating HEU-zone.

\section{References}

1. Dyakov A.S. About conversion of Russian research reactors (2015)

2. IAEA Research Reactors Database, URL: http://nucleus.iaea.org/RRDB/RR/ReactorSearch.aspx?filter=0 (access date 12.09.2015).

3. Arkhangelskiy N.V. Modern state and perspectives of works on reduction of HEU use in Russian research reactors, International conference «Global partnership of «G8» Evaluation of results and perspectives of further cooperation in the field of nuclear and radiation safety», Moscow, (2012)

4. Izhutov A.L., Ovchinnikov V.A., Romanovskiy S.V., Svistunov V.A., Svyatkin M.N. NPP life extension and perspectives of using loop research reactor MIR, 13-th annual Russian meeting «Nuclear power plants safety», Dimitrovgrad, (2011)

5. Starkov V.A., The Status of Testing LEU U-Mo Full Size IRT Type Fuel Elements and Mini-Elements in the MIR Reactor, Progress, Challenges, and Opportunities for Converting U.S. and Russian Research Reactors: A Workshop Report, the National Academies Press, Washington D.C., (2012)

6. Common statement of SAEC 'Rosatom' and United States Department of Energy on strategic directions of cooperation of the Russian Federation and the USA in the nuclear field.

URL:http://www.rosatom.ru/resources/e6ab250048a712729d44dddb97771387/sz_strateg_napravl.pdf (access date20.09.2011)

7. Research of reasons for technological possibility to convert research reactor MIR-M1 to reduced enrichment uranium fuel in JSC “SSC NIIAR", Dimitrovgrad, 2010. 